\title{
Introduction
}

Field seismics and electrical resistivity are powerful tools to investigate the surface geological reservoir rocks at depth. The two methods are complementary and have been largely used for prospection purposes of oil/gas reservoirs. To the first order, seismics allow assessing the reservoir rock porosity (Wyllie et al., 1958) and electrical resistivity is used to infer the nature and temperature of the fluid present at depths. To the second order, provided that the fluid nature is known, insights on the porosity and pore structure, hence on hydraulic conductivity, could be inferred from measured electrical properties (Archie, 1952; Glover et al., 1994; Violay et al., 2010). Indeed, both hydraulic and bulk electrical conductivity are expected to correlate as the two intrinsically depend on the amount and tortuosity of the pore network (Bernabé et al., 2003; David, 1993; Milsch et al., 2008).

To investigate precisely the effect of the porosity and pore network on the elastic and electrical transport properties, the classical method is to investigate their evolution as a function of effective confining pressure (Han et al., 2011; Pimienta et al., 2017). However, very few apparatuses exist for such method, and another way may be to artificially induce a given amount of microcracking in the rock sample by thermal treatment. For an initially isotropic rock, the procedure is expected to lead to an isotropic microfracturing of the rock sample from the sole mismatch of thermal expansion between the minerals inside the rock (Fredrich \& Wong, 1986; Nasseri et al., 2007): (i) For temperatures below $575{ }^{\circ} \mathrm{C}$, the randomly oriented anisotropic grains will expand thermally in preferred orientations thus leading to opening of inter- or intra-granular cracks; and (ii) At about $575{ }^{\circ} \mathrm{C}$ and for temperatures beyond, the quartz $\alpha-\beta$ transition occurs and may lead to intense microfracturing of the quartz-bearing rock samples.

\section{Samples preparation}

Three rock types are used for the study in order to span a range in quartz content: a sandstone, a granite and a diorite. Fontainebleau sandstone is made of randomly oriented quartz grains cemented by quartz. The rock is a homogeneous, isotropic and clean (i.e. $99.9 \%$ quartz) sandstone that has been overly used in the rock physics community (Bourbie \& Zinszner, 1985; Pimienta et al., 2014, 2015). Westerly granite is also well-known to the rock physics and rock mechanics community (Wang et al., 2013), as it is a homogeneous and isotropic crustal rock, mainly constituted of feldspars and quartz (about $30 \%$ content) grains. The diorite originates from the US and is found to be extremely stiff (i.e. loosely microcracked), and with an average content in quartz of $30 \%$, thus being a good candidate for the study of inducing microcracks in rocks.

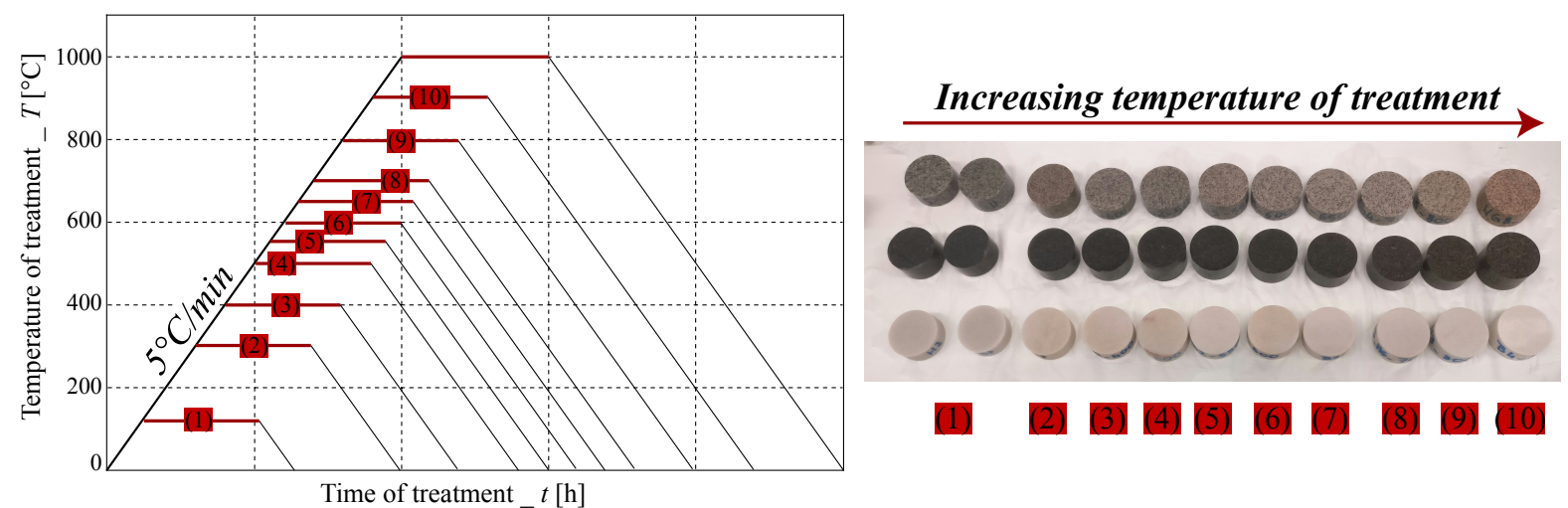

Figure 1 Schematics of thermal treatments, from slow temperature ramps of $5{ }^{\circ} \mathrm{C} /$ min increase and 1 ${ }^{\circ} \mathrm{C} /$ min decrease, on samples of three rock types. The rock types chosen are of Westerly granite, diorite and Fontainebleau sandstone of $6 \%$ porosity.

For each of the three rock types, eleven rock samples are prepared as cylinders of about $40 \mathrm{~mm}$ diameter and $20 \mathrm{~mm}$ length. Each sample is submitted to a given temperature of treatment, from $100^{\circ} \mathrm{C}$ up to $900^{\circ} \mathrm{C}$. Ten temperatures of treatment are tested in total (Fig. 1). For all sought temperatures, the same value of ramp of temperature increase is used of $5{ }^{\circ} \mathrm{C} / \mathrm{min}$. This ramp is slow enough to allow 
for temperature homogenisation inside the rock sample, which allows avoiding sudden large temperature gradients and thus thermal chocking (Wang et al., 2013).

Once the set temperature is reached, it is maintained during one hour, then the heating stops and the sample cool slowly inside the hoven. The temperature decrease was found to be about $1{ }^{\circ} \mathrm{C} / \mathrm{min}$, and is expected to be slow enough to avoid any unwanted thermal chocking. As observed from the evolution of colours of the rock samples, temperature also leads to the rock samples to gain reddish colorations. This indicates the occurrence of oxidation of minerals (probably iron-rich) in the rock samples. The reddish colour is very clear in Westerly granite samples, but much less in the diorite and not seen in the Fontainebleau sandstone. Consistently, the sandstone is almost pure quartz, i.e. not a Fe-bearing mineral that could be oxidized.

\section{Measuring methods}

Before thermal treatments, dimensions (i.e. length and diameter) and mass are measured on all rock samples. For most samples, P- and S-wave velocities along the dry sample, and porosity of the sample, are also measured. After treatment, the properties measured are: (i) dimensions, (ii) mass under dry and water-saturated conditions, (iii) P- and S-wave velocity of the dry and water-saturated sample, and (iv) electrical impedance of the brine-saturated sample.

The dimensions are obtained with an electronic calliper, accurate to about $1 \mu \mathrm{m}$, and mass is obtained with an electronic balance accurate to $1 \mathrm{mg}$. Porosity is obtained with a pycnometer, accurate to about $10^{-3} \mathrm{~cm}^{3}$, but also relying on the accuracy of the calliper-inferred rock volume and on the assumption of a perfect cylindrical rock. As a consequence, direct measurements by the calliper are additionally used for the variation in volume of the rock sample such that : $\Delta \mathrm{V}=\Delta \mathrm{L}+2 \Delta \mathrm{R}$. Ultrasonic P- and Swaveforms (i.e. $f=1 \mathrm{MHz}$ ) are acquired from applying two couples of $\mathrm{P}$ - or S-piezoelectric transducers on the opposite faces of the sample. From the recorded waveforms, P- and S-wave velocities are obtained from the travel time of the first arrival (Fig. 2a) across the sample length. Figure (2b) reports an example of P-waveforms obtained on samples of about the same length but brought to different temperatures of thermal treatments.
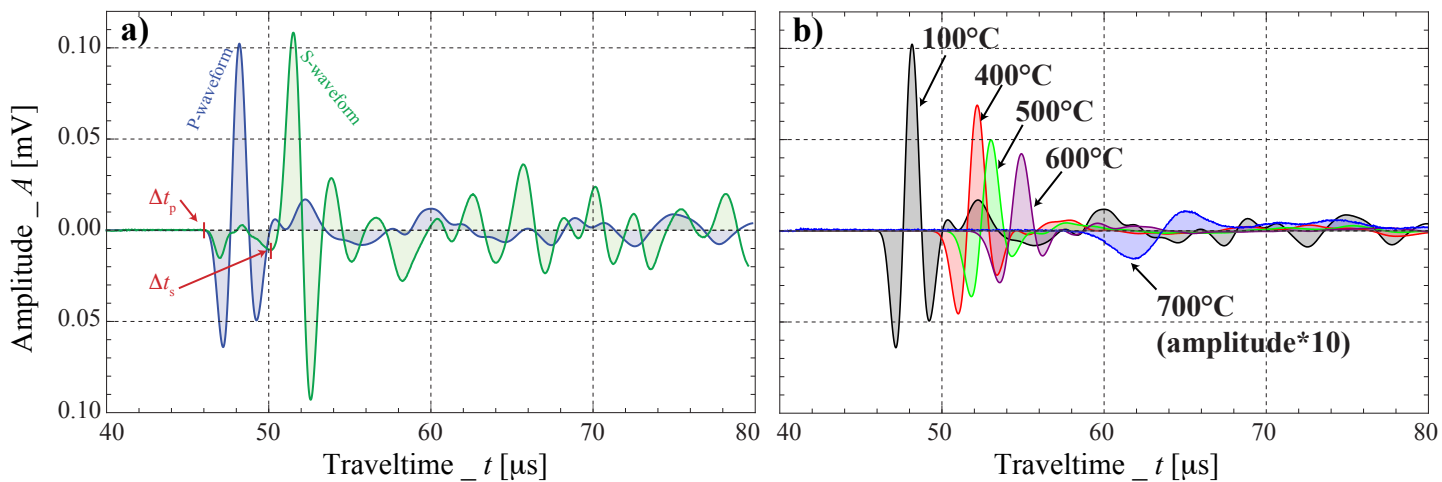

Figure 2 Principle of measurement for $P$ - and $S$ - ultrasonic wave velocities measured on dry samples (a) recorded $P$-and $S$-waveforms of the intact sample; and (b) P-waveforms of the samples submitted to temperatures between $100^{\circ} \mathrm{C}$ and $700^{\circ} \mathrm{C}$.

Electrical impedance is measured in the frequency band of $1 \mathrm{MHz}-100 \mathrm{mHz}$ on the rock samples either dry or saturated by brines of varying electrical conductivities. To investigate the electrical formation factor unbiased of the surface effects, measurements are made for brine conductivities spanning 450 $\mu \mathrm{S} / \mathrm{cm}$, for the tap water, up to $300 \mathrm{mS} / \mathrm{cm}$ for a tap water saturated by dissolved $\mathrm{NaCl}$ ions. Figure (3) shows an example of electrical impedance measured in an intact Fontainebleau sandstone sample for different fluid salinities. Electrical impedance is measured in terms of norm (Fig. 3a) and phase (Fig. 3b), or of real and imaginary parts. As observed from the signals phase, strong dissipative effects may occur for frequencies below $1 \mathrm{kHz}$. Interestingly, these dissipative effects increase with an increase in the fluid salinity. We are here interested solely in non-dissipative effects, more representative of the samples bulk electrical resistivity. Consistently with earlier works, the property is obtained at a measuring frequency of about $1 \mathrm{kHz}$. 

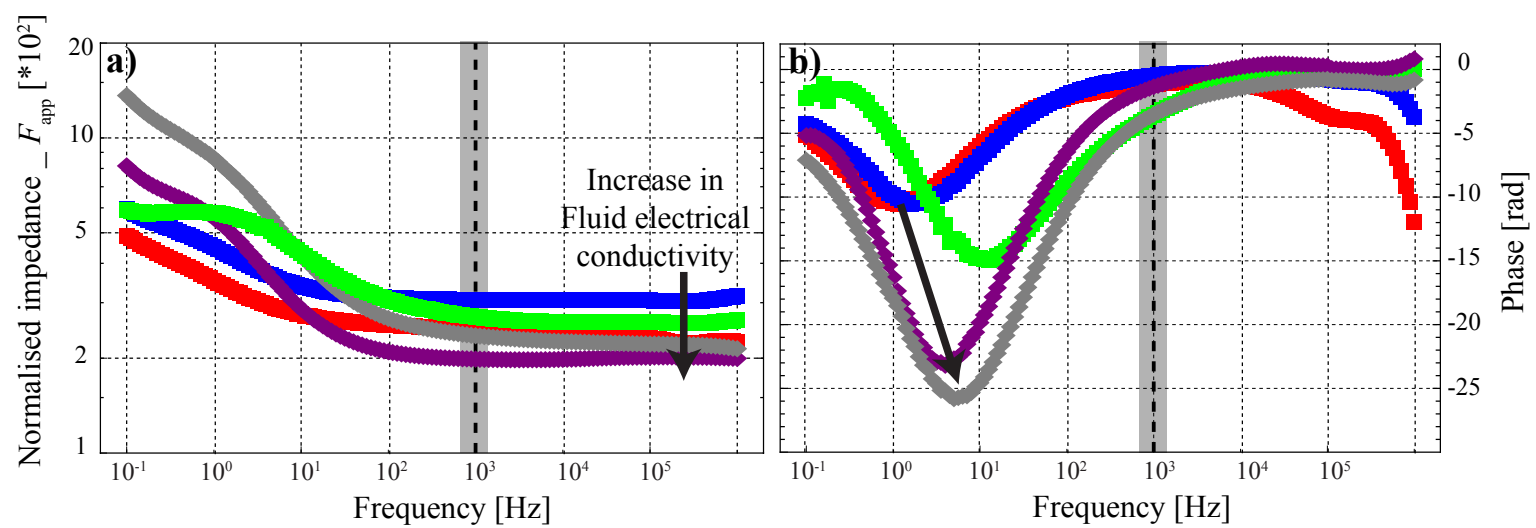

Figure 3 Principle of measurement of electrical impedance for different brines in terms of (a) norm of the signal, here pre-processed to account for the sample dimensions and fluid electrical conductivity, i.e. in terms of apparent formation factor $F_{\text {app}}$; and (b) phase of the electrical signal for the different fluid conductivities. The variability observed on $F_{\text {app }}$ beyond $1 \mathrm{kHz}$ is expected to relate to the measurement error on $F$.

\section{Preliminary results}

As highlighted in Figure (2b), waveforms amplitude decrease and traveltime increase with increasing the temperature of treatment. The effects are very strong on both P- and S-waveforms, leading in particular to important decrease in $\mathrm{P}$ - and S-wave velocities of the dry samples. This is consistent with existing results in granites (Nasseri et al., 2007), interpreted as a large increase in the microcrack density, i.e. a population of compliant thin and elongated pores. Moreover, large differences in ultrasonic elastic properties are observed between dry and water-saturated conditions, as expected from the stiffening effect of water in microcracked media (Pimienta et al., 2016). Similarly, the formation factor inferred shows also a decrease, and the porosity increases, which could be interpreted again as the increase in microfracturing of the rock sample.

However, the evolution in porosity and, most of all, in formation factor with temperature remains relatively small in the sandstone that had an initial porosity of $6 \%$. It will be shown that this aspect can be investigated in terms of interplay between two networks of pores (Bernabé, 1991; Guéguen \& Dienes, 1989; Pimienta et al., 2017): interconnected tubes and cracks. Moreover, precisely comparing the evolution of the properties with temperature shows a deviation in the temperature dependence between elastic and transport properties. This aspect is interpreted in terms of the temperaturedependent opening, or aspect ratio, of the family of microcracks.

\section{Conclusions}

A standard thermal treatments procedure is used to investigate the effect of microcracking on the elastic and transport properties of rocks. The samples are measured prior and after treatment, under dry and brine-saturated conditions, in terms of elastic and transport properties. From using three different rocks, of variable initial quartz content and porosity, it is shown that microcrack density affects differently the elastic and transport properties. Interestingly, the rock samples show very similar decrease in both P- and S-wave velocities yet very different variations in transport properties. Those differences are interpreted in terms of intrinsic contribution of the pore networks to the different properties.

\section{Acknowledgements}

This work was allowed by a dual funding from the European Research Council, under the MSCACOFUND action scheme, and from the Swiss Competence Center for Energy Research-SoE. 


\section{References}

Archie, G. E. (1952). Classification of carbonate reservoir rocks and petrophysical considerations. AAPG Bulletin, 36(2), 278-298.

Bernabé, Y. (1991). Pore geometry and pressure dependence of the transport pproperties in sandstones. Geophysics, 56(0), 436-446.

Bernabé, Y., Mok, U., \& Evans, B. (2003). Permeability-porosity Relationships in Rocks Subjected to Various Evolution Processes. Pure and Applied Geophysics, 160(5), 937-960. https://doi.org/10.1007/PL00012574

Bourbie, T., \& Zinszner, B. (1985). Hydraulic and acoustic properties as a function of porosity in Fontainebleau sandstone. Journal of Geophysical Research: Solid Earth (1978--2012), 90(B13), $11524-11532$.

David, C. (1993). Geometry of flow paths for fluid transport in rocks. Journal of Geophysical Research: Solid Earth, 98(B7), 12267-12278. https://doi.org/10.1029/93JB00522

Fredrich, J. T., \& Wong, T. (1986). Micromechanics of Thermally Induced Cracking in Threee Crustal Rocks. Journal of Geophysical Research, 91(B12), 743-764. https://doi.org/10.1029/JB091iB12p12743

Glover, P. W. J., Meredith, P. G., Sammonds, P. R., \& Murrell, S. A. F. (1994). Ionic surface electrical conductivity in sandstone. Journal of Geophysical Research: Solid Earth (1978-2012), 99(B11), 21635-21650.

Guéguen, Y., \& Dienes, J. (1989). Transport Properties of Rocks from Statistics and Percolation. Mathematical Geology, 21(1), 1-13.

Han, T., Best, A. I., Sothcott, J., \& Macgregor, L. M. (2011). Pressure effects on the joint elasticelectrical properties of reservoir sandstones. Geophysical Prospecting, 59(3), 506-517. https://doi.org/10.1111/j.1365-2478.2010.00939.x

Milsch, H., Blöcher, G., \& Engelmann, S. (2008). The relationship between hydraulic and electrical transport properties in sandstones: An experimental evaluation of several scaling models. Earth and Planetary Science Letters, 275(3-4), 355-363. https://doi.org/10.1016/j.epsl.2008.08.031

Nasseri, M. H. B., Schubnel, A., \& Young, R. P. (2007). Coupled evolutions of fracture toughness and elastic wave velocities at high crack density in thermally treated Westerly granite. International Journal of Rock Mechanics and Mining Sciences, 44(4), 601-616. https://doi.org/10.1016/j.ijrmms.2006.09.008

Pimienta, L., Sarout, J., Esteban, L., David, C., \& Clennell, M. B. (2017). Pressure-Dependent Elastic and Transport Properties of Porous and Permeable Rocks: Microstructural Control. Journal of Geophysical Research: Solid Earth. https://doi.org/10.1002/2017JB014464

Pimienta, L., Fortin, J., \& Guéguen, Y. (2014). Investigation of elastic weakening in limestone and sandstone samples from moisture adsorption. Geophysical Journal International, 199(1). https://doi.org/10.1093/gji/ggu257

Pimienta, L., Fortin, J., \& Guéguen, Y. (2015). Bulk modulus dispersion and attenuation in sandstones. Geophysics, 80(2).

Pimienta, L., Fortin, J., Borgomano, J. V. M., \& Guéguen, Y. (2016). Dispersions and attenuations in a fully saturated sandstone: Experimental evidence for fluid flows at different scales. Leading Edge, 35(6). https://doi.org/10.1190/tle35060495.1

Violay, M., Pezard, P. A., Ildefonse, B., Belghoul, A., \& Laverne, C. (2010). Petrophysical properties of the root zone of sheeted dikes in the ocean crust: A case study from Hole ODP/IODP 1256D, Eastern Equatorial Pacific. Tectonophysics, 493(1-2), 139-152. https://doi.org/10.1016/j.tecto.2010.07.013

Wang, X. Q., Schubnel, A., Fortin, J., Guéguen, Y., \& Ge, H. K. (2013). Physical properties and brittle strength of thermally cracked granite under confinement. Journal of Geophysical Research: Solid Earth, 118(12), 6099-6112. https://doi.org/10.1002/2013JB010340

Wyllie, M. R. J., Gregory, A. R., \& Gardner, G. H. F. (1958). An experimental investigation of factors affecting elastic wave velocities in porous media. Geophysics, XXIII(3), 459-493. 